\section{Endogenous Retrovirus Erv-3 Is Not Implicated in Rheumatoid Arthritis But May Provide a Biomarker for Osteoarthritis}

To the Editor:

Rheumatoid arthritis (RA) is an autoimmune disease with chronic inflammation of the synovial membrane culminating in the destruction of cartilage and bone. The etiology is unknown, although possible causes include viral triggers ${ }^{1}$. The latter may include human endogenous retroviral (HERV) families: HERV-K, HERV-L, ERV-9, and ERV-3 $3^{2,3}$. We have reported a novel reverse transcriptase polymerase chain reaction (RT-PCR) system to identify HERV-K10 and identified significantly high levels of messenger RNA in the peripheral blood (and synovial fluid) of patients with RA compared to osteoarthritis (OA) and healthy controls ${ }^{4}$. In our study, we modified the RT-PCR system to analyze ERV-3 expression in these patients.

Peripheral blood mononuclear cells (PBMC) from 20 RA patients who fulfilled American Rheumatism Association criteria were used to extract cDNA following established protocols ${ }^{5}$. The average age was 61 years (range 34-85 yrs). Seventeen patients with OA (mean age $67 \mathrm{yrs,} \mathrm{range}$ 40-92 yrs) and 27 healthy individuals (mean age $47 \mathrm{yrs}$, range 21-80 yrs) served as controls, with permission of the local ethics committee. Samples were tested in a multiplex system ${ }^{5}$, and optimized for the envelope region of ERV-3. In brief, ERV-3 sense (5'-GAG GCA TAA CTA TAG GAG ATT GGA AG-3') and antisense (5'-CTA TCC TTT CCA AGT CTG AAC TGG-3') primers were used plus a housekeeping gene, histidyl tRNA synthetase (sense: 5'-CTT CAG GGA GAG CGC GTG CG-3'; antisense: 5'-CCT TCA GGT CAT AGA TAA GC-3'). RT-PCR conditions were $94^{\circ} \mathrm{C}$ for $2 \mathrm{~min}, 30$ cycles of denaturation at $94^{\circ} \mathrm{C}$ for $30 \mathrm{~s}$, annealing at $58^{\circ} \mathrm{C}$ for $30 \mathrm{~s}$, and extension at $72^{\circ} \mathrm{C}$ for $1 \mathrm{~min}$ (plus a final extension of $6 \mathrm{~min}$ at $\left.72^{\circ} \mathrm{C}\right)$. The system was validated using cDNA extracted from cell lines (BJAB and AG876) that harbored ERV-3 ${ }^{5}$. The PCR amplicons (ERV-3 $404 \mathrm{bp}$ and HtRNA $319 \mathrm{bp}$ ) were analyzed following gel electrophoresis by measuring their pixel intensities using Scion image software (Scion, Frederick, MD, USA). A pixel ratio was obtained with reference to the housekeeping gene. All samples were tested in triplicate and the mean value obtained. DNA sequencing ${ }^{5}$ of amplicons confirmed $99 \%$ homology with ERV-3.

On testing PBMC from RA, OA, and control samples, ERV-3 messenger RNA (mRNA) expression (plus housekeeping gene) was exhibited in all samples (Table 1 ).

We conducted a 1-way ANOVA on pixel ratio intensity to investigate whether ERV-3 differed between patients (control vs OA vs RA). ANOVA revealed a significant difference between OA patients and controls ( $\mathrm{p}=$ 0.014 ). Tukey post-hoc pairwise comparison also confirmed that the only significant difference was between controls and OA patient groups (1.36 vs 2.22 , respectively) with a difference of 0.8549 (95\% CI 0.1603 to 1.5496 ). There was an elevation of ERV-3 in OA compared to RA groups but this was not statistically significant in this preliminary study.

Our data suggest that ERV-3 is not associated with RA but could provide a marker in OA. Interestingly, the lowest level of ERV-3 expression was higher in the OA group compared to healthy control and RA groups, but there was no correlation between ERV-3 expression and age in patients with OA. ERV-3 (HERV-R) is an inherited single-copy provirus mapped to chromosome 7 . It possesses a long open-reading frame in the env gene that

Table 1. Evaluation of ERV-3 in RA, OA and N groups following RT-PCR.

\begin{tabular}{lcccc}
\hline Sample & Presence & \multicolumn{2}{c}{ Pixel Intensity } & $\mathrm{p}$ \\
& of ERV-3 & Mean (Range) & SE & \\
\hline Control $(\mathrm{n}=27)$ & $27 / 27$ & $1.36(0.53-2.28)$ & 0.10 & \\
RA $(\mathrm{n}=40)$ & $40 / 40$ & $1.81(0.26-3.56)$ & 0.16 & $\geq 0.05$ \\
OA $(\mathrm{n}=17)$ & $7 / 17$ & $2.22(0.99-4.69)$ & 0.30 & 0.014 \\
\hline
\end{tabular}

is capable of producing a $65 \mathrm{kDa}$ protein, which plays a physiological role in the placenta ${ }^{6}$ and is linked to congenital heart block in infants ${ }^{7}$. The presence of ERV-3 in OA needs to be evaluated in a larger cohort of OA patients and with other suitable controls. These studies could then assess ERV-3 as a potential biomarker of this degenerative disease, which can have a genetic predisposition. Alternatively, ERV-3 expression could be a possible epiphenomenon. Overall, the availability of a simple biomarker could be useful in OA.

PAUL NELSON, BSc, PhD, Dip HE, Immunology Research Group, Research Institute in Healthcare Science, University of Wolverhampton,

Wolverhampton, WV1 1SB, UK; HORA DAVARI-EJTEHADI, BSc, PhD, Dip HE; Faculty of Health, Birmingham City University, Perry Barr, Birmingham, UK; ALAN NEVILL, BSc, PhD; SIMON BOWMAN, PhD, FRCP, Rheumatology Department, Selly Oak Hospital, Birmingham, UK. Address correspondence to Dr. P. Nelson; E-mail: p.n.nelson@wlv.ac.uk

\section{REFERENCES}

1. Nelson PN, Hooley P, Roden D, Davari Ejtehadi H, Rylance P, Warren $\mathrm{P}$, et al. Human endogenous retroviruses: Transposable elements with potential? Clin Exp Immunol 2004;138:1-9.

2. Nakagawa K, Brusic V, McColl G, Harrison LC. Direct evidence for the expression of multiple endogenous retroviruses in the synovial compartment in rheumatoid arthritis. Arthritis Rheum 1997;40:627-38.

3. Takeuchi K, Katsumata K, Ikeda H, Minami M, Wakisaka A, Yoshiki T. Expression of endogenous retroviruses, ERV3 and lambda 4-1, in synovial tissues from patients with rheumatoid arthritis. Clin Exp Immunol 1995;99:338-44.

4. Ejtehadi HD, Freimanis GL, Ali HA, Bowman S, Alavi A, Axford $\mathrm{J}$, et al. The potential of human endogenous retrovirus K10 in the pathogenesis of rheumatoid arthritis: a preliminary study. Ann Rheum Dis 2006;65:612-6.

5. Davari Ejtehadi H, Martin JH, Junying J, Roden DA, Lahiri M, Warren P, et al. A novel multiplex RT-PCR system detects human endogenous retrovirus-K in breast cancer. Arch Virol 2005; 150:177-84

6. Larsson E, Andersson AC, Nilsson BO. Expression of an endogenous retrovirus (ERV3, HERV-R) in human reproductive and embryonic tissues - evidence for a function for envelope gene products. Ups J Med Sci 1994;99:113-20.

7. Li JM, Fan WS, Horsfall AC. The expression of human endogenous retrovirus-3 in fetal cardiac tissue and antibodies in congenital heart block. Clin Exp Immunol 1996;104:388-93.

J Rheumatol 2010;37:2; doi:10.3899/jrheum.090735 